\title{
Molecular Characterization of Rotavirus Strains Circulating in Enugu Nigeria: 2011 to 2016
}

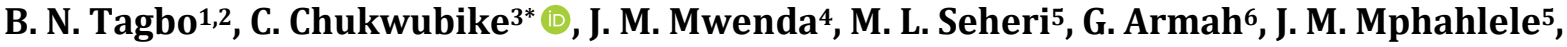 \\ U. C. Ozumba ${ }^{3}$, C. Benjamin-Puja ${ }^{3}$, C. Azubuike ${ }^{3}$, H. U. Okafor ${ }^{1,2}$, R. O. Nnani ${ }^{1}$, V. Okafor ${ }^{1}$, \\ B. O. Edelu ${ }^{2,7}$, C. B. Eke ${ }^{2,7}$, O. Udemba ${ }^{8}$, A. Isiaka ${ }^{9}$, L. Namadi' ${ }^{10}$ N. Umezinne ${ }^{3}$, R. Njoku ${ }^{8}$, \\ C. Odume ${ }^{11}$, V. Osaro' ${ }^{1}$, N. Ogude'1, M. U. Okwesili ${ }^{8}$, S. K. Ezebilo' ${ }^{1}$, K. M. Yusuf ${ }^{10}$, E. O. Obidike ${ }^{2,7}$, \\ ICH UNTH Enugu Rotavirus Group\#
}

\author{
${ }^{1}$ Institute of Child Health, University of Nigeria Teaching Hospital, Ituku-Ozalla, Enugu, Nigeria \\ ${ }^{2}$ Department of Paediatrics, University of Nigeria Teaching Hospital, Ituku-Ozalla, Enugu, Nigeria \\ ${ }^{3}$ Department of Microbiology, University of Nigeria Teaching Hospital, Ituku-Ozalla, Enugu, Nigeria \\ ${ }^{4}$ WHO African Regional Office, Brazzaville, Congo \\ ${ }^{5}$ South African Medical Research Council/Diarrhoeal Pathogens Research Unit, Department of Virology, Sefako Makgatho Health \\ Sciences University, Medunsa, Pretoria, South Africa \\ ${ }^{6}$ Noguchi Memorial Institute for Medical Research, University of Ghana, Legon, Ghana \\ ${ }^{7}$ Department of Paediatrics, College of Medicine University of Nigeria, Ituku-Ozalla, Nigeria \\ ${ }^{8}$ Mother of Christ Specialist Hospital, Enugu, Nigeria \\ ${ }^{9}$ World Health Organization Country Office, Abuja Nigeria \\ ${ }^{10}$ National Primary Health Care Development Agency, Federal Ministry of Health, Abuja, Nigeria \\ ${ }^{11}$ Tender Care Specialist Children's Hospital, Enugu, Nigeria \\ Email: *chinedumbc@yahoo.com
}

How to cite this paper: Tagbo, B.N., Chukwubike, C., Mwenda, J.M., Seheri, M.L., Armah, G., Mphahlele, J.M., Ozumba, U.C., Benjamin-Puja, C., Azubuike, C., Okafor, H.U., Nnani, R.O., Okafor, V., Edelu, B.O., Eke, C.B., Udemba, O., Isiaka, A., Namadi, L., Umezinne, N., Njoku, R., Odume, C., Osaro, V., Ogude, N., Okwesili, M.U., Ezebilo, S.K., Yusuf, K.M. and Obidike, E.O., ICH UNTH Enugu Rotavirus Group (2019) Molecular Characterization of Rotavirus Strains Circulating in Enugu Nigeria: 2011 to 2016. World Journal of Vaccines, 9, 22-36.

https://doi.org/10.4236/wjv.2019.91002

Received: November 28, 2018 Accepted: February 17, 2019 Published: February 20, 2019

\begin{abstract}
Rotavirus gastroenteritis is a major public health concern globally, estimated to cause 215,000 deaths among children $<5$ years of age in 2013; with majority of mortality occurring in developing countries. In 2013, it was estimated that Nigeria was the second country with the highest number of rotavirus deaths. Monitoring of circulating rotavirus strains in Enugu, Nigeria is part of on-going rotavirus surveillance before the introduction of rotavirus vaccination. A total of 2694 stool samples were collected from enrolled under 5 years old children with diarrhoea between January 2011 and December 2016 and tested the virus using an antigen enzyme immunoassay. Randomly selected rotavirus positive samples were further characterized by rotavirus genotype methods to identify the $\mathrm{G}$ and $\mathrm{P}$ types circulating during the study period. Rotavirus was detected in 1242 (46\%) of the 2694 samples collected over the six years period. Of these, 867 were randomly selected for genotyping. $\mathrm{G}$ and P types could be assigned for 832 samples (96\%), while 31 (3.6\%) could only
\end{abstract}

${ }^{\#}$ F. Akpali, N. Nwankwo, D. Ezenwaka, P. Nwachukwu, P. Oha, N. Anioke, A. Okonkwo, I. Onwusi, Past team members. 
Copyright $\odot 2019$ by author(s) and Scientific Research Publishing Inc. This work is licensed under the Creative Commons Attribution International License (CC BY 4.0).

http://creativecommons.org/licenses/by/4.0/

Open Access be assigned either genotype G or P (partially typed) and 4 (0.4\%) could not be assigned genotype $\mathrm{G}$ and $\mathrm{P}$ (untypeable). The most common G-genotypes detected during the entire study period were G12, G1 and G3 accounting for 27.6\%, 21.0\% and 16.3\% respectively. Mixed G and P-genotypes were commonly detected. Ninety-one of the samples, representing $10.8 \%(91 / 839)$ had mixed G-genotype whilst 130 of the samples representing $15.2 \%(130 / 852)$ had mixed P-genotype. The most common P-genotypes detected were P[8], $\mathrm{P}[6]$ and $\mathrm{P}[4]$ representing $38.3 \%, 35.4 \%$ and $9.1 \%$ respectively. The predominant strain detected was G12P[8] (22.3\%) followed by G3P[6] (14.5\%), G1P[8] (9.2\%) and G1P[6] (8.0\%). These data are useful for making an informed decision about the introduction of rotavirus vaccine into the national routine immunization program and to monitor the impact of the vaccine post licensure.

\section{Keywords}

Rotavirus, Molecular Characterization, Children, Genotype

\section{Introduction}

Rotavirus gastroenteritis is a major public health concern globally, estimated to cause 215, 000 (range, 197,000 - 233,000) deaths among children $<5$ years of age in 2013. Four countries (India, Nigeria, Pakistan, and Democratic Republic of Congo) accounted for approximately half (49\%) of all estimated rotavirus deaths in 2013 [1]. In Africa, Nigeria has one of the highest under 5 years rotavirus disease prevalence of 56\% [2] and mortality due to rotavirus accounted for an estimated 31,000 deaths in 2013 [3]. Since improved sanitation, water supply and hygiene have little or no effect on rotavirus infections [2] [4] [5], vaccination is predicated to have great impact on rotavirus diarrhoea in Nigeria. Vaccines against rotavirus are available and have been shown to be effective in countries where they were employed [6] [7]. Rotavirus surveillance is ongoing in Enugu State to determine the burden of rotavirus disease and circulating strains in anticipation of the introduction of rotavirus vaccine into the routine immunization schedule of Nigeria in 2019.

Rotavirus is a segmented RNA virus belonging to the Reoviridae family. The two outer surface proteins VP7 and VP4 are used to classify the virus into G and P types which independently stimulate the production of neutralizing antibodies [8]. Molecular typing of these genes has provided important epidemiological information on the diversity of rotavirus strains in circulation [9]. Currently, about 35 G-genotypes and 50 P-genotypes have been described in humans and animals worldwide (https://rega.kuleuven.be/cev/viralmetagenomics/virus-classification/rcwg). Of these genotypes, $12 \mathrm{G}$ types and $15 \mathrm{P}$ types have been found in humans [10]. Six genotype combinations (G1P[8], G2P[4], G3P[8], G4P[8], G9P[8] and G12[P8]) have been identified globally following epidemiological surveys to be responsible for $80 \%-90 \%$ 
of majority of severe rotavirus infections worldwide [11] [12] [13] [14] [15]. In developing countries, the diversity of unusual strains is greater and more strains circulate concurrently at any time [16]. For instance, a WHO surveillance report noted the predominance of uncommon rotavirus strains including G12P[6]; G2P[6], G3P[6], G1P[6]; G1P[4], G2P[8]; and G9P[4] circulating in South East Asia; sub-Saharan Africa; West Pacific and the Americas respectively [17].

Rotavirus diarrhoea surveillance was established in Nigeria in September 2010 as part of the African Rotavirus Surveillance Network with the support of the World Health Organization (WHO). The Institute of Child Health, University of Nigeria Teaching Hospital, Ituku-Ozalla, Enugu was chosen by the Ministry of Health to play a dual role of Paediatric hospital and National laboratory for rotavirus surveillance. Neighbouring hospitals including Tender Care Specialist Hospital, and Mother of Christ Specialist Hospital, both in Enugu are part of surveillance.

This surveillance data reports the circulating rotavirus strains in Nigeria between January, 2011 and December, 2016.

\section{Methods}

This surveillance was conducted as part of the WHO supported rotavirus diarrhoea disease in Enugu, South Eastern, Nigeria, the capital city of Enugu State, Nigeria. Many inhabitants of the state are Nigerians of Igbo ethnic nationality. The main occupations of the inhabitants are public service, trading and agriculture-including animal rearing.

Between January 2011 and December 2016, stool samples were collected from children less than 5 years that were hospitalized with gastroenteritis at three main sites. These are; Children Emergency Room (CHER) of the University of Nigeria Teaching Hospital (UNTH) Ituku-Ozalla, Enugu (main site), Tender Care Specialist Hospital Enugu and Mother of Christ Specialist Hospital (MOCSH) Enugu. Inclusion and exclusion for rotavirus cases were based on the WHO generic protocol [18]. The surveillance protocol was approved by the Health Research Ethics Committee of the University of Nigeria Teaching Hospital, Ituku-Ozalla, Enugu. Demographic and clinical information were collected following the generic protocol of the World Health Organization on surveillance for rotavirus gastroenteritis [18] after informed consent had been obtained from mothers or care givers of children.

Sampling: Stool specimens were obtained mostly within 48 hours after admission to exclude nosocomial infections. The stool samples were collected in clean and well labelled screw-capped containers and delivered to the laboratory within one hour or stored temporarily at $+4^{\circ} \mathrm{C}$ to $+8^{\circ} \mathrm{C}$ in hospitals before transporting under ice to the Virology Laboratory at University of Nigeria Teaching Hospital (UNTH) Ituku-Ozalla, Enugu. At the main laboratory, stool samples were stored at $-60^{\circ} \mathrm{C}$ till used. All demographic and clinical data were recorded on a standardized WHO Case Report Form and analyzed using SPSS 
Version 17.0 software.

\subsection{Rotavirus Detection}

Group A rotaviruses were detected by enzyme immunoassay (EIA) with the commercial rotavirus Prospect ${ }^{\circledR}$ Rotavirus Kit, (Oxoid LTD, United Kingdom) provided by WHO/AFRO on $10 \%$ suspensions of faecal material, according to the manufacturer's instructions.

Rotavirus positive samples were subsequently sent to the WHO Regional Rotavirus Reference Laboratories (RRL) at South African Medical Research Council, Diarrhoeal Pathogens Research Unit, Sefako Makgatho Health Sciences University (SMU), Pretoria and Noguchi Memorial Institute of Medical Research, University of Ghana, Accra. Rotavirus positive samples were further subjected to semi nested reverse-transcriptase polymerase chain reaction (RT-PCR).

\subsection{Viral RNA Extraction and RT-PCR}

Double-stranded RNA (dsRNA) was extracted from 10\% faecal suspension of rotavirus EIA-positive and PAGE positive stool samples by the Phenol/Chloroform method as described previously [19] and purified with the RNaid ${ }^{\mathbb{B}}$ Kit (Bio 101, Carlsbad, USA). The VP7 and VP4 genes of rotavirus were subjected to RT-PCR followed by multiplex PCR according to the methods described by Gouvea et al., [20] in a Gene AMP PCR Primus 25 System machine. Consensus primer sets that were published [21] [22] [23] were used to amplify the VP4 and VP7 gene segments of the rotavirus. Genotyping of the $G$ and $P$ were done with multiplex type specific primers [21] [22] [23] to detect G1 to G4, G8, G9, G10 and G12 and $\mathrm{P}[4], \mathrm{P}[6], \mathrm{P}[8], \mathrm{P}[10] \mathrm{P}[11]$ respectively. The PCR products were electrophoresed on $2.0 \%$ agarose gel containing ethidium bromide $(0.5 \mathrm{ug} / \mathrm{ml})$ (Sigma-Aldrich, Steinheim, Germany) and visualized under UV transilluminator.

\section{Results}

Of a total of 2694 stool samples collected from children under 5 years of age with AGE during 2011-2016 1242 (46\%) were rotavirus positive by enzyme immunosorbent assay (EIA). Eight hundred and sixty-seven (867) were randomly collected to ensure representative samples for entire year for genotyping. $\mathrm{G}$ and $\mathrm{P}$ types was assigned for 832 samples (96\%), while 31 (3.6\%) could only be assigned either genotype G or P (partially typed) and $4(0.4 \%)$ could not be assigned genotype G and P (untypeable). Among the G-types, G12 ( $\mathrm{n}=239$, $27.6 \%)$ followed by $\mathrm{G} 1(\mathrm{n}=182 ; 21.0 \%)$ and $\mathrm{G} 3(\mathrm{n}=141 ; 16.3 \%)$ were the dominant genotypes. Out of the 8 G-types detected in this study, G4 $(\mathrm{n}=10$, $1.2 \%)$ was the least found genotype while $3.2 \%$ were found to be non-typable (Table 1). P-types revealed that out of the 4 P-types detected P [8] $(\mathrm{n}=332$; $38.3 \%)$ was the predominant genotype. This was followed by $\mathrm{P}[6](\mathrm{n}=307$, $35.4 \%)$ and $P[4](n=79 ; 9.1 \%)$. Similarly $1.7 \%$ of the strains were found to be non-typable (Table 1$)$. 
Table 1. Rotavirus G and P-genotypes detected in children $<5$ years old hospitalized with acute watery diarrhoea.

\begin{tabular}{|c|c|c|c|c|c|c|c|c|c|c|c|}
\hline \multirow{2}{*}{ P-Type } & \multicolumn{11}{|c|}{ G-Type } \\
\hline & G1 & G2 & G3 & G4 & G8 & G9 & G10 & G12 & GMIX & GNT & TOTAL (\%) \\
\hline $\mathrm{P}[4]$ & 2 & 47 & 2 & 0 & 0 & 9 & 1 & 5 & 10 & 3 & $79(9.1)$ \\
\hline $\mathrm{P}[6]$ & 69 & 8 & 126 & 1 & 6 & 17 & 42 & 11 & 20 & 7 & $307(35.4)$ \\
\hline $\mathrm{P}[8]$ & 80 & 5 & 4 & 8 & 0 & 10 & 4 & 193 & 18 & 10 & $332(38.3)$ \\
\hline $\mathrm{P}[10]$ & 2 & 0 & 0 & 0 & 0 & 1 & 1 & 0 & 0 & 0 & $4(0.5)$ \\
\hline PMIX & 25 & 7 & 8 & 1 & 0 & 6 & 7 & 29 & 43 & 4 & $130(15.0)$ \\
\hline PNT & 4 & 1 & 1 & 0 & 0 & 3 & 1 & 1 & 0 & 4 & $15(1.7)$ \\
\hline TOTAL (\%) & $182(21.0)$ & $68(7.8)$ & $141(16.3)$ & $10(1.2)$ & $6(0.7)$ & $46(5.3)$ & $56(6.5)$ & 239 (27.6) & $91(10.5)$ & $28(3.2)$ & $867(100)$ \\
\hline
\end{tabular}

Numbers in parenthesis are percentage of each sample. Mix indicates at least $2 \mathrm{G}$ or P found in one sample. NT means non-typable samples.

Of the 832 samples that were assigned both $\mathrm{G}$ and P-genotype specificity, $79.0 \%(\mathrm{n}=654)$ were single $\mathrm{G}$ and P-genotypes. The most prevalent strains detected were G12P[8] (23.2\% [193/832]) followed by G3P[6] (15.1\%[126/832]), G1P $[8]$ (9.6\% [80/832) and G1P[6] (8.3\% [69/832]) (Table 1). These 4 strains constituted $56.5 \%$ of acute diarrhoea cases during the study period. Non-typeable rotavirus G-types accounted for 3.2\% (28/867) and the P-types accounted for $1.7 \%(15 / 867)$ in the 6 years study period (Table 1$)$. Uncommon and/or rare rotavirus strains, G1P[10], G1P[4], G3P[4] were detected at $0.2 \%$ each whilst G10P[10], G9P[10] and G10P[4] were detected at $0.1 \%$ each (Table 1). Other uncommon and/or rare strains detected include; G2P[6] (1\%), G2P[8] (0.6\%), G12P[4] (0.6\%), G8P [6] (0.7\%), G10P[8] (0.4\%) and G9P[4] (1.1\%). Some of the samples characterized exhibited both mixed G and P genotypes (15\%; 130/867) (Table 1).

\section{Temporal year by year Rotavirus strain distribution in Enugu, Nigeria.}

G12P[8] occurred as the prevalent strain in 2011 (24.2\%; 39/162), 2012 (46.4\%; 65/140) and $2013(27 \%$; 45/167) whilst G1P[8] was the dominant strain in $2014(18.3 \%$; 19/104) and $2015(22 \% ; 35 / 159)$ (Table 2). In 2016 G3P[6] emerged as the most common strain (14.8\%; 20/135). G3P[6] was detected in 2011, 2014 and 2015 as the second most common strain at 21\%, (34/162); 17.3\% (18/104) and 19.0\% (30/159) respectively whilst G10P[6] was shown to be the second prevailing strain in $2012(15.7 \%$ [22/140]) and $2013(9.6 \%$ [16/167]) (Table 2). In the year 2016, the second most common strain was G2P[4] (13.3\% [18/135]).

Table 3 shows rotavirus genotype distribution by age. Rotavirus was detected in children of all age groups enrolled in the routine surveillance. It was predominantly detected in children $<12$ months $(67.6 \%$; 586/867) followed by those who are 12 - 23 months old (26.4\%) and the $24-59$ months age group (6\%). The most prevalent strain was (G12P[8]) detected in $67.4 \%$ (130/193) of children < 12 months. A consistent decrease from $67.4 \%$ to $27.5 \%$ (53/193) was seen in children between the ages of 12 - 23 months and 5.2\% (10/193) in children 
Table 2. Annual distribution of major rotavirus stains in children $<5$ years hospitalized with acute watery diarrhoea in Nigeria: 2011-2016.

\begin{tabular}{|c|c|c|c|c|c|c|c|}
\hline $\mathrm{G}$ and $\mathrm{P}$ combinations & 2011 & 2012 & 2013 & 2014 & 2015 & 2016 & Total (\%) \\
\hline G1P[6] & 3 & 6 & 11 & 14 & 21 & 14 & $69(8.0)$ \\
\hline G1P[8] & 10 & 1 & 2 & 19 & 35 & 13 & $80(9.2)$ \\
\hline $\mathrm{G} 2 \mathrm{P}[4]$ & 24 & 0 & 1 & 1 & 3 & 18 & $47(5.4)$ \\
\hline G3P[6] & 34 & 10 & 14 & 18 & 30 & 20 & $126(14.5)$ \\
\hline G9P[6] & 1 & 0 & 3 & 3 & 1 & 8 & $16(7.8)$ \\
\hline G9P[8] & 1 & 0 & 7 & 2 & 1 & 0 & $11(1.3)$ \\
\hline G10P[6] & 2 & 22 & 16 & 2 & 0 & 0 & $42(4.8)$ \\
\hline G12P[6] & 1 & 2 & 5 & 1 & 1 & 1 & $11(1.3)$ \\
\hline $\mathrm{G} 12 \mathrm{P}[8]$ & 39 & 65 & 45 & 16 & 20 & 8 & $193(22.3)$ \\
\hline Others & 7 & 0 & 34 & 11 & 1 & 5 & $58(6.7)$ \\
\hline Mixed genotypes & 28 & 24 & 25 & 13 & 44 & 45 & $179(20.6)$ \\
\hline Partially typed & 11 & 10 & 4 & 2 & 1 & 3 & $31(3.6)$ \\
\hline Non typable & 1 & 0 & 0 & 2 & 1 & 0 & $4(0.5)$ \\
\hline Total (\%) & $162(18.7)$ & $140(16.1)$ & $167(19.3)$ & $104(12)$ & $159(18.3)$ & $135(15.6)$ & $867(100.0)$ \\
\hline
\end{tabular}

Mixed genotype indicates at least $2 \mathrm{G}$ or $\mathrm{P}$ found in one sample. Partially typed indicates both the G or P is typed and the other is not. Only genotypes with at least 10 samples were represented, the rest were grouped as others.

Table 3. Major rotavirus strains distribution by age circulating among children $<5$ years old with diarrhoea in Enugu Nigeria: 2011-2016.

\begin{tabular}{ccccc}
\hline \multirow{2}{*}{ G AND P GENOTYPES } & \multicolumn{3}{c}{ AGE GROUP (Months) } & \multirow{2}{*}{ Total } \\
\cline { 2 - 4 } G1P[6] & \multicolumn{1}{c}{ MONTHS } & 12 TO 23 MONTHS & 24 TO 59 MONTHS & \\
G1P[8] & 41 & 22 & 6 & 69 \\
G2P[4] & 53 & 23 & 4 & 80 \\
G3P[6] & 32 & 12 & 3 & 47 \\
G9P[6] & 98 & 22 & 6 & 126 \\
G9P[8] & 14 & 2 & 0 & 16 \\
G10P[6] & 8 & 2 & 1 & 11 \\
G12P[6] & 26 & 12 & 4 & 42 \\
G12P[8] & 6 & 5 & 0 & 11 \\
Others & 130 & 53 & 10 & 193 \\
Mixed Genotypes & 114 & 19 & 6 & 58 \\
Partially typed & 28 & 53 & 12 & 31 \\
Non-typable & 3 & 3 & 0 & 479 \\
Total (\%) & $586(67.6)$ & $229(26.4)$ & $52(6.0)$ & $867(100.0)$ \\
\hline
\end{tabular}

Mixed genotype indicates at least $2 \mathrm{G}$ or $\mathrm{P}$ found in one sample. Partially typed indicates both the G or $\mathrm{P}$ is typed and the other is not. Mix. Only genotypes with at least 10 samples were represented, the rest were grouped as others. 
between 24 - 59 months. This was followed by both mixed G and P genotypes with $64.0 \%(114 / 179)$ detected in children < 12 months, $29.6 \%(53 / 179)$ in children between 12 - 23 months and 6.7\% (12/179) in children between 24 - 59 months (Table 3).

There were more males than females enrolled during the surveillance period. Rotavirus strain distribution by gender showed infection was higher in males compared to females (58\% vs 42\%) (Table 4). G12P[8], G3P[6], G1P[6], G1P[8], G10P[6] and G2P[4] were the most prevalent strains and caused $59.4 \%$ of severe gastroenteritis in male children $<5$ years in Enugu, Nigeria. The strain distribution in females that presented with acute diarrhoea in the surveillance showed that the predominant strain was G12P[8], followed by G3P [6], G1P[8], G1P[6] and G2P[4] representing 59.7\% of cases (Table 4). A high proportion of mixed genotypes was detected in both males and females $(20.3 \%$ and $21 \%)$ respectively. Monthly distribution of rotavirus strains during the study period showed that $97 \%$ of strains were detected in the dry cool months of December to April (Figure 1). G12P [8] was the most prevalent strain (97.4\%; 188/193) detected during the peak season for acute gastroenteritis in the dry cool months of December to April followed by G3P[6] (96\%; 121/126). The prevalence of G12P[8] strain decreased from 27\% (121/453) in January to 9.6\% (20/208) in February. However, there was a return of G12P[8] in March (15\%; 10/67), April (25.6\%; 11/43) and December $(37.7 \% ; 26 / 69)$. G3P[6], the second most common strain detected

Table 4. Distribution of major rotavirus strains by gender in Enugu Nigeria: 2011-2016.

\begin{tabular}{cccc}
\hline \multirow{2}{*}{ G AND P GENOTYPES } & \multicolumn{2}{c}{ GENDER } & Total \\
\cline { 2 - 3 } G1P[6] & MALE & FEMALE & \\
G1P[8] & 45 & 24 & 69 \\
G2P[4] & 40 & 40 & 80 \\
G3P[6] & 26 & 21 & 47 \\
G9P[6] & 73 & 53 & 126 \\
G9P[8] & 9 & 7 & 16 \\
G10P[6] & 7 & 4 & 11 \\
G12P[6] & 28 & 14 & 42 \\
G12P[8] & 8 & 3 & 193 \\
Others & 114 & 79 & 58 \\
Mixed genotypes & 36 & 22 & 179 \\
Partially types & 102 & 77 & 31 \\
Non-typable & 13 & 18 & $867(100.0)$ \\
Total (\%) & 2 & 2 & 464 \\
\hline
\end{tabular}

Mixed genotype indicates at least $2 \mathrm{G}$ or P found in one sample. Partially typed indicates both the G or P is typed and the other is not. Only genotypes with at least 10 samples were represented, the rest were grouped as others. 


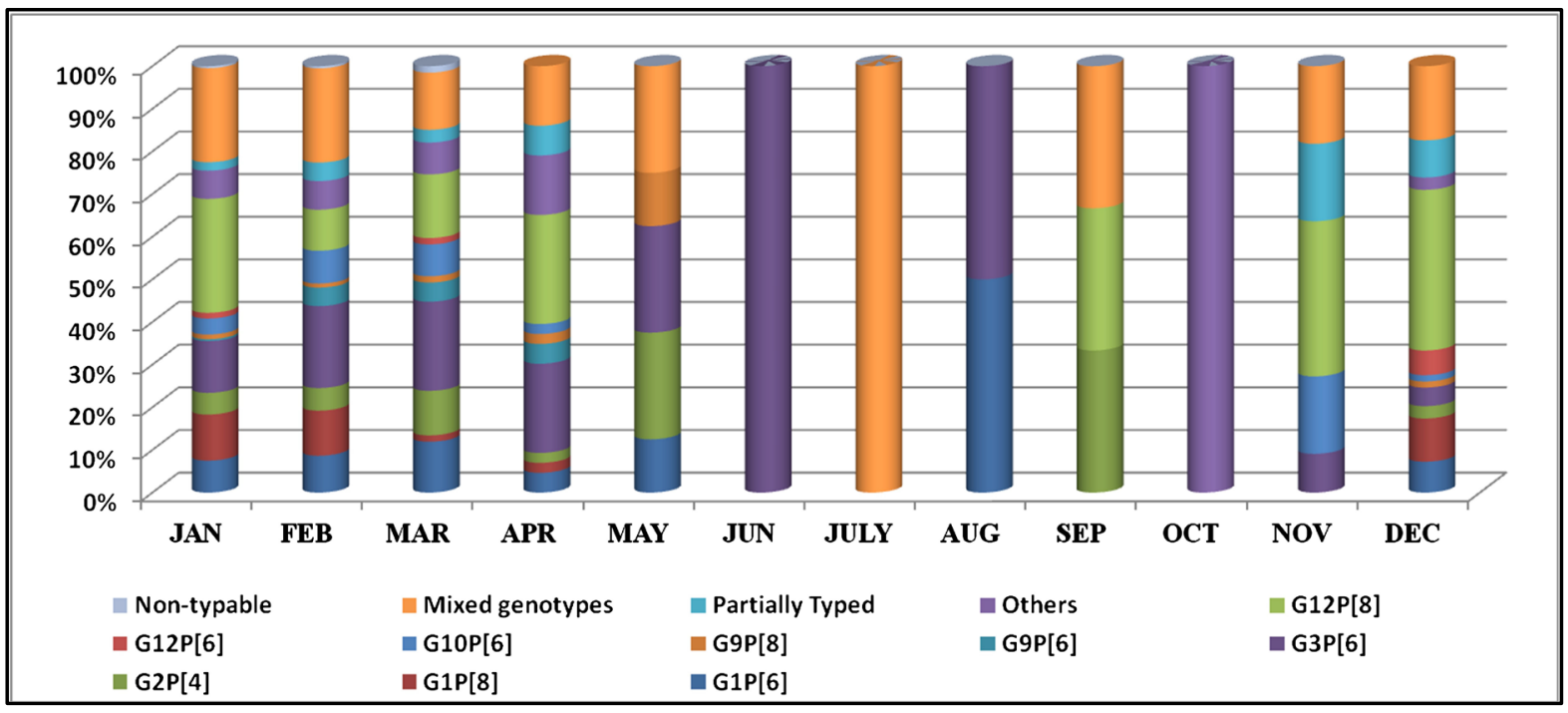

Figure 1. Seasonality of rotavirus strains in children $<5$ years old hospitalized with acute diarrhoea in Enugu, Nigeria: 2011-2016.

during the peak season was dominant in March (21\%; 14/67) and April (21\%; 9/43) followed by January (12\%; 55/453) and February (19\%; 40/208) (Figure 1).

\section{Discussion}

Rotavirus continues to be the leading cause of severe gastroenteritis among children below the age of 5 years globally [1]. We report the detection and characterization of rotavirus strains in Enugu, Nigeria during 2011-2016. Our Surveillance has shown that rotavirus accounted for $46 \%$ of diarrheal episodes in children less than 5 years of age. This confirms previous reports in other African countries such as Cameroon, Ethiopia, Tanzania, Zimbabwe, Togo and Ghana where rotavirus prevalence was found to be between $23 \%$ - 49\% [24] [25] [26] [27]. Rotavirus with G12 genotype specificity was the most commonly detected (27.6\%) of genotyped samples. This finding is in conformance to previous studies in Ile-Ife, South West Nigeria [28] and Maiduguri, North East Nigeria [29]. It is however, in sharp contrast to earlier reports from Nigeria where G1 genotype dominated [30] [31] [32]. The detection of G12 genotype has also been reported from other African countries including Niger Republic, Ghana, Togo and Nepal in Asia [26] [27] [33] [34] [35].

Epidemiological studies demonstrated that G1P[8], G2P [4], G3P [8], G4P [8], G9P [8], and G12P [8] are responsible for $80 \%-90 \%$ of most rotavirus infections among children less than 5 years old worldwide [11] [12] [13]. However, these globally common strains constituted only $41.5 \%$ of detected rotavirus strains in Enugu, Nigeria. G12P[8], G3P[6], G1P[8] and G1P[6] were the most prevalent in this study and accounted for $56.5 \%$ of strains characterized. Genotyping of human rotavirus revealed a great diversity in genotype combinations in Enugu, Nigeria. This increase in strain diversity could be due to natural epidemiological changes of rotavirus strains circulating. The observed increase in diversity could 
be explained by naturally occurring selection pressures and viral evolution in Enugu, Nigeria. Though cross protection with natural infection and vaccine-induced immunity have been reported [35] [36] [37] [38], the observed diversity of rotavirus strains in Nigeria should be monitored post vaccine introduction. One of the major finding of this surveillance report was the high proportion of mixed infections accompanied by the presence of multiple rotavirus $\mathrm{P}$ and $\mathrm{G}$ (strain) combinations, suggesting genome reassortment. However, other studies have also reported mixed infections [36] [39] [40]. Non-typeable rotavirus G-types accounted for 3.2\% (28/867) and the P-types accounted for 1.7\% $(15 / 867)$ in the 6 years study period (Table 1$)$. This is in contrast to other studies carried out in the Regional Rotavirus Reference Laboratory in Ghana where higher proportions of non-typeable rotavirus strains had been documented [27] [41]. The reduction in the proportion of non-typeable rotavirus strains was due to the use of expanded genotyping primer sets and sequence analysis (although more expensive) currently available in the two Rotavirus reference laboratories in South Africa and Ghana.

In our study area, rotavirus occurred mostly during December to April. This corresponded to the dry season in Nigeria and elsewhere in West Africa [41] [42] [43] [44] [45]. Rotavirus infection showed a smooth rise in January and started declining in February through March and April to November. A rise was seen again during the cool dry month of December (Figure 1). The monthly distribution of rotavirus strain observed in this surveillance period is in accordance with findings reported previously [7] [42]. The peak season for rotavirus infection was in January $(52.2 \%$; 435/867) followed by February $(24 \%$; 208/867), December (8\%; 69/867) March (7.7\%) and April (5\%; 43/867). Rotavirus infection displays distinct seasonal pattern in temperate climates with epidemic peaks occurring in the cooler winter months of the year and absent or uncommon during the warmer months of the year [46] [47]. In tropical areas rotavirus disease has been reported to occur all year round with seasonal peaks occurring during the cool dry months of the year [48] [49] [50].

More males were recruited into the study and were found to be infected with higher proportions of rotavirus strains $(58 \%$; 503/876) than the females $(42 \%$; 364/867) ( $\mathrm{P}<0.05)$. Rotavirus was detected in children of all age groups, but the highest detection rate was observed in children $<12$ months (67.6\%; 586/867). The rate of detection in children between the ages of 12 - 23 months was $26.4 \%$ whilst those between $24-59$ months were $6 \%$. It is interesting to note that G12P[8] was the most prevalent strain detected in all the age groups. Mixed genotypes were also seen mainly in children less than 12 months old. The proportion of mixed infection observed in the present study (15\%) is higher than previous reports from Southern Nigeria [31] [50] and lower than the report by Aminu et al. [30] of Northern Nigeria. It is however, in accordance with findings reported previously elsewhere and some African countries [47] [48] [51] [52]. The study has demonstrated that rotavirus infection as well as the most prevalent strains occurred in children below the age of 24 months. 
Seasonal variations in the prevalence of some rotavirus strains were observed. The most common prevailing strain in the study from 2011-2013 was G12P[8], the sixth globally common circulating strain. However, the distribution pattern of this strain in Enugu, Nigeria changed during 2014-2016. The 2014-2015 year saw the emergence of G1P [8] the globally most common strain, replacing G12P[8] detected during the first three years of the study period. In 2016, G3P[6] an unusual strain, emerged as the dominant strain. G3P[6] was established as the second commonly detected strain in 2011, 2014 and 2015 whilst G10P[6] was detected as the second common strain in 2012 and 2013. G1P[6] an unusual strain was identified as the second dominant strain in 2016. G1P[8] the most common rotavirus strain detected globally, was virtually non-existent during 2012 and 2013. Some unusual rotavirus strains documented in this study (G1P[6], G3P [6], G12P[6] and G12P[6] occurred all year round (Figure 1, Table 2).

\section{Conclusion}

We report the prevalence of rotavirus $G$ and $P$ genotypes circulating in infants and children in Enugu, Nigeria pre-rotavirus vaccine introduction. The predominant strains identified as part of routine rotavirus surveillance reflect the great diversity and unusual nature of rotavirus strains detected in Nigeria. This data will be useful in supporting evidence-based decisions on introduction of rotavirus vaccine into the national immunization programme in Nigeria.

\section{Acknowledgements}

We thank the Chief Medical Directors of the participating hospitals-Amah CC and Okafor MI. We also acknowledge the contributions of former team members and supporting institutions.

\section{Disclosures}

The authors have declared no competing conflict of interest or funding disclosure.

\section{Funding}

This work was funded by the WHO and GlaxoSmithKline Biologicals. GlaxoSmithKline Biologicals SA was given the opportunity to review a preliminary version of this manuscript for factual accuracy. However, they had no role in the surveillance design, data collection, analysis and the decision to publish the manuscript. The authors are solely responsible for the final content and interpretation of the work.

\section{References}

[1] Tate, J.E., Burton, A.H., Boschi-Pinto, C., Parashar, U.D., et al. (2016) Global, Regional, and National Estimates of Rotavirus Mortality in Children $<5$ Years of Age, 2000-2013. Clinical Infectious Diseases, 62, S96-S105.

https://doi.org/10.1093/cid/civ1013 
[2] Tagbo, B.N., Mwenda, J.M., Armah, G., Obidike, E.O., Okafor, U.H., Oguonu, T., et al. (2014) Epidemiology of Rotavirus Diarrhea among Children younger than 5 years in Enugu, South East Nigeria. The Pediatric Infectious Disease Journal, 33, S19-S22. https://doi.org/10.1097/INF.0000000000000047

[3] World Health Organization (2016) Estimated Rotavirus Death for Children under 5 Years of age 2013. World Health Organization Bulletin 2016. http://www.who.int/vaccine_safety/committee/reports/wer8907.pdf?ua=1

[4] Parashar, U.D., Burton, A., Lanata, C., Boshchi-Pinto, C., Shibuya, K., Steele, D., et al. (2009) Global Mortality Associated with Rotavirus Disease among Children in 2004. The Journal of Infectious Disease, 200, S9-S15. https://doi.org/10.1086/605025

[5] Rodrigues, F., Iturriza-Gomara, M., Marlow, R., et al. (2013) The Evolving Epidemiology of Rotavirus Gastroenteritis in Central Portugal with Modest Vaccine Coverage. Journal of Clinical Virology, 56, 129-134.

https://doi.org/10.1016/j.jcv.2012.10.016

[6] Block, S.L., Vesikari, T., Goveia, M.G., Rivers, S.B., Adeyi, B.A., Dalla, M.J., et al. (2007) Pentavalent Rotavirus Vaccine Dose Confirmation Efficacy Study Group. Efficacy, Immunogenicity, and Safety of a Pentavalent Human-Bovine (WC3) Reassortant Rotavirus Vaccine at the end of Shelf Life. Pediatrics, 119, 11-18.

https://doi.org/10.1542/peds.2006-2058

[7] Armah, G.E., Sow, S.O., Breiman, R.F., Dallas, M.J., Tapia, M.D., Feikin, D.R., et al. (2010) Efficacy of Pentavalent Rotavirus Vaccine against Severe Rotavirus Gastroenteritis in Infants in Developing Countries in Sub-Saharan Africa: A Randomised, Double-Blind, Placebo-Controlled Trial. Lancet, 376, 606-614. https://doi.org/10.1016/S0140-6736(10)60889-6

[8] Matthijnssens, J., Ciarlet, M., McDonald, S., Attoui, H., Banyai, K, Brister, J., et al. (2011) Uniformity of Rotavirus Strain Nomenclature Proposed by the Rotavirus Classification Working Group (RCWG). Archives of Virology, 156, 1397-1413. https://doi.org/10.1007/s00705-011-1006-Z

[9] Gouvea, V., de Castro, L., Timenetsck, M., et al. (1994) Rotavirus Serotype G5 Associated with Diarrhea in Brazilian Children. Journal of Clinical Microbiology, 32, 1408-1409. https://www.ncbi.nlm.nih.gov/pubmed/8051281

[10] Solberg, O.D., Hasing, M.E., Trueba, G. and Eisenberg, J.N. (2009) Characterization of Novel VP7, VP4, and VP6 Genotypes of Previously Untypeable Group A Rotavirus. Virology, 385, 58-67. https://doi.org/10.1016/j.virol.2008.11.026

[11] Maes, P., Matthijnssens, J., Rahman, M. and Van Ranst, M. (2009) Rotac: A Web-Based Tool for the Complete Genome Classification of Group A Rotaviruses. BMC Microbiology, 9, 238. https://doi.org/10.1186/1471-2180-9-238

[12] Patel, M.M., Steele, D., Gentsch, JR., Wecker, J., Glass, R.I. and Parashar, U.D. (2011) Real-World Impact of Rotavirus Vaccination. The Pediatric Infectious Disease Journal, 30, S1-S5. https://doi.org/10.1097/INF.0b013e3181fefalf

[13] Iturriza-Gomara, M., Dallman, T., Banyai, K., Bottiger, B., Buesa, J., Diedrich, S., et al. (2011) Rotavirus Genotypes Co-Circulating in Europe between 2006 and 2009 as Determined By Eurorotanet, A Pan-European Collaborative Strain Surveillance Network. Epidemiology and Infection, 139, 895-909.

https://doi.org/10.1017/S0950268810001810

[14] Estes, M.K. and Greenberg, H.B. (2013) Rotaviruses. In: Knipe. D.M. and Howley, P.M., Eds., Rotaviruses, 6th Edition, Wolters Kluwer/Lippincott Williams \& Wilkins Health, Philadelphia, PA, 1347-1401. 
[15] Desselberger, U. (2014) Rotaviruses. Virus Research, 190, 75-96. https://doi.org/10.1016/j.virusres.2014.06.016

[16] Santos, N. and Hoshino, Y. (2005) Global Distribution of Rotavirus Serotypes/Genotypes and Its Implication for the Development and Implementation of an Effective Rotavirus Vaccine. Reviews in Medical Virology, 15, 29-56.

https://doi.org/10.1002/rmv.448

[17] WHO (2011) Global Rotavirus Information and Surveillance Bulletin. Rotavirus Surveillance Data Reporting Period. January-December 2010. http://www.who.int/nuvi/rotavirus/en/index.html

[18] WHO (2002) Generic Protocols (I) Hospital-Based Surveillance to Estimate the Burden of Rotavirus Gastroenteritis in Children and (II) a Community Based Survey on Utilization of Health Care Services for Gastroenteritis in Children Immunization, Vaccines and Biologicals.

[19] Steele, A.D. and Alexander, J.J. (1987) Molecular Epidemiology of Rotaviruses in Black Infants in South Africa. Journal of Clinical Microbiology, 25, 2384-2387. https://www.ncbi.nlm.nih.gov/pmc/articles/PMC269494/

[20] Gouvea, V., Glass, R.I., Woods, P., Taniguchi, K., Clark, H., et al. (1990) Polymerase Chain Reaction Amplification and Typing of Rotavirus Nucleic Acid from Stool Specimens. Journal of Clinical Microbiology, 28, 276-282. https://www.ncbi.nlm.nih.gov/pmc/articles/PMC269590/

[21] Gentsch, J.R., Glass, R.I., Woods, P., Gouvea, V., Gorziglia, M., Flores, J., et al. (1992) Identification of Group A Rotavirus Gene 4 Types by Polymerase Chain Reaction. Journal of Clinical Microbiology, 30, 1365-1373. https://www.ncbi.nlm.nih.gov/pmc/articles/PMC265294/

[22] Das, B.K., Gentsch, J.R., Cicirello, H.G., Woods, P.A., Gupta, A., Ramachandran, M., et al. (1994) Characterization of Rotavirus Strains from Newborns in New Delhi, India. Journal of Clinical Microbiology, 32, 1820-1822. https://www.ncbi.nlm.nih.gov/pmc/articles/PMC263808/

[23] Iturriza-Gómara, M., Cubitt, D., Desselberger, U. and Gray, J. (2001) Amino Acid Substitution within the VP7 Protein of G2 Rotavirus Strains Associated with Failure to Serotype. Journal of Clinical Microbiology, 39, 3796-3798. https://doi.org/10.1128/JCM.39.10.3796-3798.2001

[24] Djeneba, O., Damintoti, I., Denis, N.W., Marie Christella, N., Virgilo, P., Virgillio, P., et al. (2007) Prevalence of Rotavirus, Adenovirus and Enteric Parasites among Pediatric Patients Attending Saint Camille Medical Centre in Ouagadougou. Pakistan Journal of Biosciences, 10, 4266-4270. https://scialert.net/abstract/?doi=pjbs.2007.4266.4270

[25] Mwenda, J.M., Ntoto, K.M., Abebe, A., Enweronu-Laryea, C., Amina, I., Mchomvu, J., et al. (2010) Burden and Epidemiology of Rotavirus Diarrhea in Selected African Countries: Preliminary Results from the African Rotavirus Surveillance Network. The Journal of Infectious Disease, 202, S5-S11. https://doi.org/10.1086/653557

[26] Tsolenganu, E., Sleheri, M., Dagnra, A., Djadou, E., Tigossou, S., Nyaga, M., et al. (2014) Surveillance for Rotavirus Gastroenteritis in Children Less than 5 Years of Age in Togo. The Pediatric Infectious Disease Journal, 33, S14-S18. https://doi.org/10.1097/INF.0000000000000046

[27] Enweronu-Laryea, C., Sogeo, K.W., Damanka, S., Lartey, B. and Armah, G. (2013) Rotavirus Genotypes Associated with Childhood Severe Acute Diarrohea in Southern Ghana: A Cross Sectional Study. Virology Journal, 10, 287. https://doi.org/10.1186/1743-422X-10-287 
[28] Oluwatonyi, J.M., Adeyemi, A.O., Famurewa, O., Svensson, L., Nordgren, J., et al. (2012) Molecular Epidemiology of Rotavirus and Noroviruses in Ile-Ife Nigeria; High Prevalence of G12P[8] Rotavirus Strains and Detection of Rare Norovirus Genotypes. Journal of Medical Virology, 84, 1489-1496. https://doi.org/10.1002/jmv.23343

[29] Ianiro, G., Delogu, R., Baba, M., Oderinde, B.S., Dawurung, J., Ruggeri, P.M. and Fiore, L. (2015) Molecular Characterization of Group A Rotavirus Strains Detected in Children with Diarrhoea Admitted to Nigerian Hospitals in 2013. Achieves of Virology, 160, 1511-1517. https://doi.org/10.1007/s00705-015-2389-Z

[30] Aminu, M., Page, N.A., Ahmad, A.A., Umoh, J., Drawer, G. and Steele, D. (2010) Diversity of Rotavirus VP7 and VP4 Genotypes in North Western Nigeria. Journal of Infectious Diseases, 202, S198-S204. https://doi.org/10.1086/653570

[31] Ayolabi, C.I., Ojo, D.A. and Armah, G.E. (2013) Electrotropherotypes and G-Types of Group A Rotavirus Detected in Children with Diarrhea in Lagos, Nigeria. ISRN Virology, 2013, Article ID: 179871.

[32] Iyoha, O. and Abiodun, P.O. (2015) Human Rotavirus Genotypes Causing Acute Watery Diarrhoea among Under-Five Children in Benin City Nigeria. Nigerian Journal of Clinical Practice, 18, 48-51. https://www.ncbi.nlm.nih.gov/pubmed/25511343

[33] Page, A.-L., Jusot, V., Mamaly, A.A., Ademou, L., Kaplon, J., Pothier, P., et al. (2014) Rotavirus Surveillance in Urban and Rural areas of Niger. April 2010-March 2012. Emerging Infectious Diseases, 20, 573-580. https://doi.org/10.3201/eid2004.131328

[34] Ndez, V.N., Papp, H., Achidi, E.A., Gonsu, K.H., Laszlo, B., Farkas, S., et al. (2013) One Year Survey of Human Rotavirus Strains Suggests the Emergence of Genotype G12 in Cameroon. Journal of Medical Virology, 85, 1485-1490. https://doi.org/10.1002/jmv.23603

[35] Dhital, S., Sherchand, J., Pokhrel, B.M., Parajuli, K., Shah, N., Mishra, S., et al. (2017) Molecular Epidemiology of Rotavirus Causing Diarrhoea among Children less than Five Years of Age Visiting National Level Children Hospital, Nepal. BMC Peadiatrics, 17, 101. https://doi.org/10.1186/s12887-017-0858-0

[36] Madhi, S.A., Cunliffe, N.A., Steele, D., Witte, D., Kirsten, M., Louw, C., et al. (2010) Effect of Human Rotavirus Vaccine on Severe Diarrhea in African infants. The New England Journal of Medicine, 362, 289-298. https://doi.org/10.1056/NEJMoa0904797

[37] Richardson, V., Hernandez-Pichardo, J., Quintanar-Solares, M., Esparza-Aguilar, M., Johnson, B., Gomez-Altamirano, C.M., et al. (2010) Effect of Rotavirus Vaccination on Death from Childhood Diarrhea in Mexico. The New England Journal of Medicine, 362, 299-305. https://doi.org/10.1056/NEJMoa0905211

[38] Vesikari, T., Matson, D.O., Dennehy, P., Van Damme, P., Santosham, M., Rodriguez, Z., et al., for The Rotavirus Efficacy Safety Trial (REST) Study Team (2006) Safety and Efficacy of Pentavalent Human-Bovine (WC3) Reassortant Rotavirus Vaccine in Preventing Rotavirus Gastroenteritis and Reducing Associated Health Care Resource Utilization. The New England Journal of Medicine, 354, 23-33. https://doi.org/10.1056/NEJMoa052664

[39] Jain, V., Das, B.K., Bhan, M.K., Glass, R.I. and Gentsch, J.R., The Indian Strain Surveillance Collaborating Laboratories (2001) Great Diversity of Group A Rotavirus Strains and High Prevalence of Mixed Rotavirus Infections in India. Journal of Clinical Microbiology, 39, 3524-3529. 
https://doi.org/10.1128/JCM.39.10.3524-3529.2001

[40] Todd, S., Page, N.A., Steele, D.S., Peenze, I. and Cunliffe, N.A. (2010) Rotavirus Strain Types Circulating in Africa: Review of Studies Published during 1997-2006. The Journal of Infectious Disease, 202, S34-S42. https://doi.org/10.1086/653555

[41] Bonkoungou, I., Damanka, S., Sanou, I., Tiendrebeogo, F., Coulibaly, S., Bon, F., et al. (2011) Genotype Diversity of Group A Rotavirus Strains in Children with Acute Diarrhea in Urban Burkina Faso, 2008-2010. Journal of Medical Virology, 83, 1485-1490. https://doi.org/10.1002/jmv.22137

[42] Binka, F.N., Anto, F.K., Oduro, A.R., Awini, E.A., Nazzar, A.K., et al. (2003) Incidence and Risk Factors of Paediatric Rotavirus Diarrhoea in Northern Ghana. Tropical Medicine and International Health, 8, 840-846. https://doi.org/10.1046/j.1365-3156.2003.01097.x

[43] Rodrigues, A., de Carvalho, M., Monteiro, S., Mikkelson, S.C., Aaby, P., Molbakk, K., et al. (2007) Hospital Surveillance of Rotavirus Infection and Nosocomial Transmission of Rotavirus Disease among Children in Guinea-Bissau. The Pediatrtic Infectious Disease Journal, 26, 233-237. https://www.ncbi.nlm.nih.gov/pubmed/17484220 https://doi.org/10.1097/01.inf.0000254389.65667.8b

[44] Akran, V., Peenze, I., Akoua-Koffi, C., Kette, H., De Beer, M.C., Dosso, M. and Steele, A.D. (2010) Molecular Characterization and Genotyping of Human Rotavirus Strains in Abidjan, Cote d'Ivoire. The Journal of Infectious Disease, 202, S220-S224. https://doi.org/10.1086/653567

[45] Damanka, S., Adiku, T., Armah, G., Rodrigues, O., Donkor, E., Nortey, D., et al. (2016) Rotavirus Infection in Children with Diarrhea at Korle-Bu Teaching Hospital, Ghana. Japanese Journal of Infectious Diseases, 69, 331-334.

[46] Mutanda, L.N., Kinoti, S.N., Gemert, W. and Lichenga, E.O. (1984) Age Distribution and Seasonal Pattern of Rotavirus Infection in Children in Kenya. Journal of Diarrhoeal Disease Research, 2, 147-150. https://www.ncbi.nlm.nih.gov/pubmed/6512214\#

[47] Puerto, F.I., Polanco, G.G., Gonzalez, M.R., Zavala, J.E. and Otega, G. (1989) Role of Enteric Adenovirus in Acute Paediatric Diarrhoea at an Urban Hospital in Mexico. Transaction of the Royal Society of Tropical Medicine and Hygiene, 83, 396-398. https://www.ncbi.nlm.nih.gov/pubmed/2559506\# https://doi.org/10.1016/0035-9203(89)90515-4

[48] Biritwum, R.B., Isomura, S., Yamaguchi, H., Toba, M. and Mingle, J.A. (1984) Seroepidemiological Study of Rotavirus Infection in Rural Ghana. Annals of Tropical Paediatrics, 4, 237-240. https://doi.org/10.1080/02724936.1984.11748343

[49] Armah, G.E., Mingle, J.A., Dodoo, A.K., Anyanful, A., Antwi, R., Commey, J. and Nkrumah, F.K. (1994) Seasonality of Rotavirus Infection in Ghana. Annals of Tropical Paediatrics, 14, 223-229. https://www.ncbi.nlm.nih.gov/pubmed/7825996\# https://doi.org/10.1080/02724936.1994.11747721

[50] Uzoma, E.B., Chukwubikem, C., Omoyibo, E. and Tagbo, O. (2016) Rotavirus Genotypes and the Clinical Severity of Diarrhoea among Under-Five Years of Age. Nigeria Postgraduate Medical Journal, 23, 1-5. https://doi.org/10.4103/1117-1936.180108

[51] Boula, A., Waku-Kouomou, D., Njiki Kinkela, M., Esona, M., Kemajou, G., Mekontso, D., et al. (2014) Molecular Surveillance of Rotavirus Strains Circulating in Yaoundé, Cameroon, September 2007-December 2012. Infection, Genetics and Evolution, 28, 470-475. https://doi.org/10.1016/j.meegid.2014.08.019 
[52] Pukuta, E., Esona, M., Mkongolo, A., Seheri, M., Makasi, M., Nyembwe, M., et al. (2014) Molecular Surveillance of Rotavirus Infection in the Democratic Republic of the Congo August 2009 to June 2012. Paediatric Infectious Disease Journal, 33, 355-359. https://doi.org/10.1097/INF.0000000000000212 